\title{
Trends in tobacco consumption and incidences of associated neoplasms in Papua New Guinea
}

\author{
EUAN M SCRIMGEOUR, DAMIEN JOLLEY
}

\begin{abstract}
From 1960 to 1979 total annual consumption of tobacco in Papua New Guinea increased from 573 to 1800 metric tonnes. The annual consumption of tobacco per head increased from 2.78 to $6.14 \mathrm{~kg}$, and the proportion of commercial cigarettes smoked is estimated to have increased from $20 \%$ to $71 \%$ of the total tobacco consumption. Between 1965 and 1979 the average annual age standardised incidence of reported cases of carcinoma of the oral cavity increased significantly in women $(p<0.01)$ but not in men $(p>0.05)$. This rise might have been related to increasing consumption of tobacco or alcohol, or both, in individuals who habitually chewed betel nut. There was no significant change in the reported incidences of carcinoma of the larynx, lung, oesophagus, pancreas, kidney, or bladder. At present there are no constraints on the marketing of tobacco in Papua New Guinea.
\end{abstract}

\section{Introduction}

The relation between the consumption of tobacco and disease has been extensively studied. There is a significant association between the consumption of tobacco and the incidences of carcinoma of the oral cavity, oesophagus, larynx, lung, bladder, kidney, and, to a lesser extent, pancreas. ${ }^{1-3}$ The incidence of neoplasia is related to the type and quantity of tobacco smoked, the method of smoking, and the duration of exposure. Cigarette smoking is believed to cause carcinoma of the oral cavity, oesophagus, larynx, and lung, and is particularly associated with the last three. ${ }^{1-4}$ Various other factors that may contribute to the oncogenesis of certain neoplasms associated with tobacco consumption include betel nut chewing, alcohol consumption, and exposure to various chemicals.

A delay of several decades is usually apparent between the first exposure to tobacco and the development of neoplasia. This has been well documented in lung and laryngeal carcinoma. ${ }^{5-8}$ Since 1960 the consumption of tobacco, especially commercial cigarettes, has risen rapidly in Papua New Guinea. ${ }^{10}$ The present study was undertaken to ascertain if the incidence rates of neoplasms related to tobacco consumption had changed significantly since 1960 Department of Clinical Sciences, Faculty of Medicine, University of
Papua New Guinea

E M SCRIMGEOUR, FRACP, DTM\&H, senior lecturer in medicine

Papua New Guinea Institute of Medical Research, Madang, Papua New Guinea

D JOLLEY, BSC, DIPED, research fellow

Correspondence to: Dr E M Scrimgeour, 51 Woodroyd Street, Mount Lawley, Western Australia 6050.

\section{Materials and methods}

The total annual consumption of tobacco recorded in Papua New Guinea since 1960 and the total number of cigarettes and amount of twist and coarse-cut tobacco consumed annually until 1975 were obtained from the Department of Primary Industry of Papua New Guinea. (Twist and coarse-cut tobaccos are cured naturally by enzymatic fermentation and are smoked in pipes or rolled into cigars or cigarettes using leaves or newsprint.) Accurate figures for cigars and cigarettes after 1975 are not available, but estimates of commercial cigarette consumption until 1979 have been calculated from figures supplied by the Bureau of Statistics of Papua New Guinea. ${ }^{10}$

The number of cases of carcinoma of the oral cavity, oesophagus, larynx, lung, bladder, kidney, and pancreas reported annually since 1960 were obtained from the Tumour Registry of Papua New Guinea. This registry was started in 1958 and notification of neoplasms was made compulsory by law.

The age specific incidence rates for each neoplasm were obtained for men and women for the four quinquennia 1960-4, 1965-9, 1970-4, and 1975-9. These rates were calculated from population estimates obtained by the bureau of statistics from national censuses in 1966 and 1980. The 1966 census was based on a $10 \%$ population sample count whereas the 1980 census was a total count. Estimation of the total population of men and women for each of the four quinquennia was obtained by extrapolation.

The annual age standardised incidence rates for the four quinquennia were calculated and from these the average rate for each neoplasm was obtained. As the numbers in the population aged 65 or more were comparatively few, the standard truncated population was adopted for the study. ${ }^{11}$

\section{Results}

The figure shows that from 1960 to 1979 annual tobacco consumption rose from 573 to about 1800 metric tonnes. From 1960 to 1979 the annual consumption of tobacco per head increased from $2 \cdot 78$ to $6 \cdot 14 \mathrm{~kg}$. When children under 10 years are excluded, the annual consumption of tobacco per head for 1960 and 1979 would have been 4.03 and $8.8 \mathrm{~kg}$ respectively.

From 1960 to 1975, annual consumption of commercial cigarettes increased from $20 \%$ to $61 \%$ and annual consumption of twist and coarse-cut tobacco declined from $70 \%$ to $38 \%$ of the total tobacco consumption respectively. The balance of tobacco percentages was accounted for by commercial cigar consumption. It has been estimated that in 1979 total sales of commercial cigarettes rose to 1280 metric tonnes or $71 \%$ of the total tobacco consumption. ${ }^{11}$

Table I lists the average annual age standardised incidence rates for men and women for each of the seven neoplasms significantly related to tobacco consumption for the periods 1960-4, 1965-9, 1970-4 and 1975-9. Table II presents a statistical analysis of these rates for carcinomas of the oral cavity, lung, larynx, and oesophagus for the quinquennia 1965-9 and 1975-9. (The 1965-9 quinquennia rather than the 1960-4 quinquennia was chosen for comparison as the population data from the earlier census were less accurate than that obtained in the 1980 census.)

The incidence of carcinoma of the oral cavity increased significantly in women $(p<0.01)$ but not in men $(p-0.05)$ during the study period. The incidence of carcinoma of larynx, lung, oesophagus, pancreas, kidney, or blacider did not change significantly in either sex. 


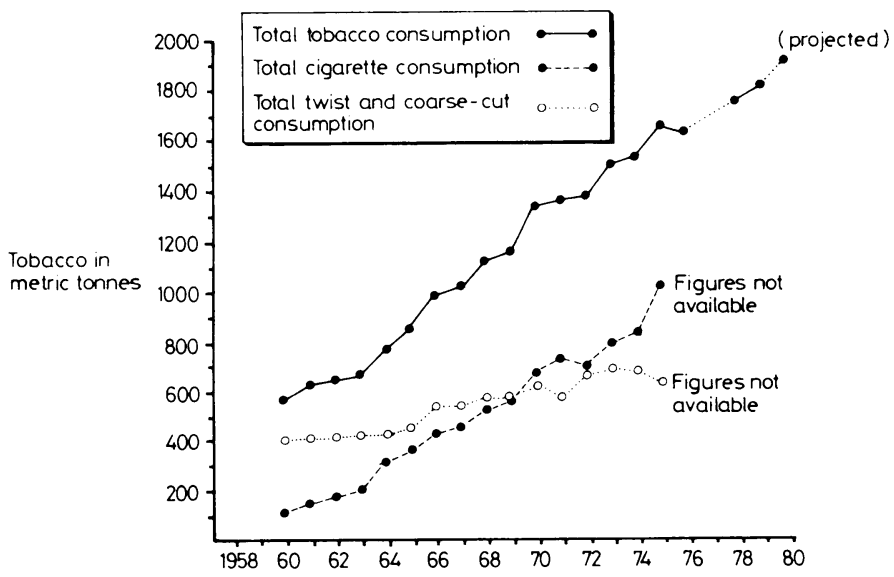

Total tobacco consumption in metric tonnes in Papua New Guinea for 1960-79; total consumption of commercial cigarette and twist and coarse-cut tobacco between 1960 and 1975 .

TABLE I-Average annual age standardised incidence rates per 100000 men and women for neoplasms related to tobacco consumption for the four quinquennia $1960-4,1965-9,1970-4$, and $1975-9$

\begin{tabular}{lccc}
\hline Neoplasm & Quinquennia & Men & Women \\
\hline Oral cavity & $1960-4$ & $10 \cdot 77$ & $2 \cdot 73$ \\
& $1965-9$ & $9 \cdot 89$ & $4 \cdot 13$ \\
& $1970-4$ & $10 \cdot 91$ & $4 \cdot 17$ \\
Larynx & $1975-9$ & $12 \cdot 79$ & $9 \cdot 07$ \\
& $1960-4$ & $0 \cdot 69$ & $0 \cdot 12$ \\
& $1965-9$ & $1 \cdot 85$ & $0 \cdot 05$ \\
Lung & $1970-4$ & $2 \cdot 10$ & $0 \cdot 35$ \\
& $1975-9$ & $1 \cdot 84$ & $0 \cdot 18$ \\
& $1960-4$ & $1 \cdot 77$ & $0 \cdot 62$ \\
Oesophagus & $1965-9$ & $2 \cdot 38$ & $0 \cdot 58$ \\
& $1970-4$ & $1 \cdot 58$ & $0 \cdot 14$ \\
& $1975-9$ & $1 \cdot 50$ & $0 \cdot 49$ \\
Pancreas & $1960-4$ & $1 \cdot 76$ & $0 \cdot 0$ \\
& $1965-9$ & $1 \cdot 70$ & $0 \cdot 55$ \\
& $1970-4$ & $0 \cdot 99$ & $0 \cdot 26$ \\
Kidney & $1975-9$ & $2 \cdot 04$ & $0 \cdot 26$ \\
& $1960-4$ & $0 \cdot 32$ & $0 \cdot 04$ \\
& $1965-9$ & 0.33 & $0 \cdot 43$ \\
Bladder & $1970-4$ & $0 \cdot 24$ & $0 \cdot 0$ \\
& $1975-9$ & $0 \cdot 05$ & $0 \cdot 0$ \\
& $1960-4$ & $0 \cdot 41$ & $0 \cdot 06$ \\
& $1965-9$ & $0 \cdot 04$ & $0 \cdot 27$ \\
& $1970-4$ & $0 \cdot 0$ & $0 \cdot 07$ \\
& $1975-9$ & $0 \cdot 06$ & $0 \cdot 0$ \\
& $1960-4$ & $0 \cdot 26$ & $0 \cdot 17$ \\
& $1965-9$ & $0 \cdot 87$ & $0 \cdot 11$ \\
& $1970-4$ & $0 \cdot 0$ & $0 \cdot 12$ \\
& $1975-9$ & $0 \cdot 83$ & $0 \cdot 28$ \\
& & & \\
\hline
\end{tabular}

\section{Discussion}

The decline in the demand for tobacco in developed countries resulting from increased public awareness of the dangers of smoking together with government restraints on the marketing of tobacco has induced tobacco companies to extend their operations in the Third World, ${ }^{12}$ and Papua New Guinea is no exception to this trend." Between 1960 and 1979 the annual consumption of tobacco per head increased by $121^{\prime}{ }^{\prime \prime}$, reaching an estimated $6 \cdot 14 \mathrm{~kg}$ in 1979 . This is relatively high by world standards, which in 1980 were estimated to range from $0.44 \mathrm{~kg}$ in Africa to $3.33 \mathrm{~kg}$ in North America. ${ }^{1:}$ The high consumption may be partly because most Papua New Guineans are largely self sufficient in food and housing, and any available money may be spent on luxuries such as tobacco.

As in other developing countries ${ }^{13-15}$ there is a rapidly rising demand for cigarettes made from flue-cured tobacco. ${ }^{10}$ Papua New Guinean tobacco prepared in this way has tar concentrations in the middle range compared with Australian and New Zealand cigarettes. " Although the tar concentrations are lower than in air-cured tobacco, the flue-cured tobacco burns at higher temperatures and increased concentrations of carcinogenic substances are produced. In addition, more smoke is inhaled.

At present there are no constraints on the production and marketing of tobacco and in fact there has been a considerable rise in domestic tobacco production, which rose from 60 metric tonnes in 1977 to 375 in 1980 . It was expected that Papua New Guinea would reach $50 \%$ self sufficiency in tobacco production by $1982 .{ }^{\prime \prime \prime}$

The number of cases recorded by the tumour registry for all neoplasms in this study was small. Most notifications came from base hospitals with surgical and radiological facilities. Probably many patients with neoplasms who lived in remote areas were not registered. Many patients with grave illness present late or refuse surgery. Terminally ill patients are usually sent home to die, and the hospital necropsy rate is low.

Underreporting of cases was particularly likely in the earlier years before the health services were well established. Improvements in access to diagnostic facilities with increased receptiveness of the populace to Western medical care would be expected to increase the numbers of patients presenting for treatment. In general, however, these factors apply equally to all neoplasms under consideration.

Only in regard to reported cases of carcinoma of the oral cavity in women does there appear to have been a significant increase in the annual average age standardised incidence between 1965-9 and 1975-9. The increase in the rate for men is not significant $(p>0.05)$. The ease of obtaining a biopsy specimen probably results in more cases of this carcinoma being registered. The obvious beneficial effects of treatment may have induced more patients to present over the period. Nevertheless, reports of rodent ulcer have not increased over the same period.

Table III indicates that carcinoma of the oral cavity is reported principally from the coastal provinces, although most of the population lives in the highlands. This neoplasm is related equally to smoking pipes, cigars, and cigarettes. ${ }^{2}$ Interestingly, a significant rise in incidence has been noted only in women as evidence suggests a considerable increase in cigarette smoking recently by certain women in the coastal regions. The results of two surveys conducted in $1968^{16}$ and in 1981 (E M Scrimgeour. Annual Symposium, Medical Society of Papua New Guinea, 1982) indicated that the proportion of adult women on the south coast of Papua who smoked commercial cigarettes increased from $33.8 \%$ to $76 \%$ over the period. Table

TABLE II-Statistical analysis of the average annual age standardised incidence rates for men and women for 1965-9 and 1975-9 for carcinoma of the oral cavity, lung, larynx, and oesophagus related to tobacco consumption

\begin{tabular}{llllllc}
\hline Neoplasm & Sex & RR & LCL & UCL & Z & p \\
\hline Oral cavity & Men & 1.194 & 0.925 & 1.500 & 1.535 & $>0.05$ \\
& Women & 1.545 & 1.087 & 2.196 & 2.425 & 0.01 \\
Lung & Men & 0.629 & 0.172 & 2.300 & 0.701 & $>0.5$ \\
& Women & 1.018 & 0.327 & 3.167 & 0.030 & $>0.25$ \\
Larynx & Men & 1.039 & 0.521 & 2.072 & 0.101 & $>0.25$ \\
Oesophagus & Women & 0.994 & 0.241 & 4.100 & 0.008 & $>0.25$ \\
& Men & 1.049 & 0.549 & 1.852 & 0.163 & $>0.25$ \\
& Women & 0.493 & 0.178 & 1.368 & 1.359 & $>0.5$ \\
& & & & & & \\
\hline
\end{tabular}

$\mathrm{RR}=$ Relative risk

LCL $=$ Lower $95 "$ ", confidence limit for relative risk.

UCL = Upper 95"," confidence limit for relative risk.

Relative risk

Standard error

TABLE III-Tobacco smoking and betel nut chezing habits in Papua New Guinean highland and coastal populations, 1968 and 1981

\begin{tabular}{|c|c|c|c|c|}
\hline & \multicolumn{2}{|c|}{1968} & \multicolumn{2}{|c|}{1981} \\
\hline & Men & Women & Men & Women \\
\hline $\begin{array}{l}\text { New Guinea highlands:* } \\
\text { robacco smokers } \\
\text { Betel nut chewers }\end{array}$ & $\begin{array}{l}74 \cdot 5 \\
46\end{array}$ & $\begin{array}{r}78.3 \\
1.9\end{array}$ & $\begin{array}{l}77 \\
26 \cdot 7\end{array}$ & $\begin{array}{r}80 \\
1\end{array}$ \\
\hline $\begin{array}{l}\text { Papuan south coast: } \\
\text { Tobacco smokers } \\
\text { Betel nut chewers }\end{array}$ & $\begin{array}{l}76 \cdot 5 \\
79\end{array}$ & $\begin{array}{l}33 \cdot 8 \\
83 \cdot 8\end{array}$ & $\begin{array}{l}85 \\
71 \cdot 4\end{array}$ & $\begin{array}{l}76 \\
66 \cdot 7\end{array}$ \\
\hline
\end{tabular}

* 1968 survey was conducted in Mount Hagen and the 1981 survey in Goroka. 
IV shows that the increase in the proportion of women living on the south coast of Papua and women and men in the highlands who smoked cigarettes was less pronounced. Coastal people as a rule smoke commercial cigarettes only whereas highlanders smoke both commercial cigarettes and home cured tobacco. ${ }^{16}$ The smoking trends noted on the south coast of Papua probably apply to many other coastal areas as well.

Interpretation of the increase in the incidence rate in women and to a lesser extent men must also include consideration of the possible role of betel nut chewing, which is widespread, especially in coastal areas where the areca palm (Areca catechu $L$ ) which produces the betel nut grows. The nut is chewed together with the betel pepper (Piper betel) and slaked lime. Betel nut is chewed by both sexes, often from childhood. Table IV indicates that betel nut chewing is more popular on the Papuan coast than in the highlands, principally because it is expensive to import betel nut from the coast. (Mount Hagen has better access to areca palm growing areas than does Goroka, which may account for the observation that more Mount Hagen men chewed betel nut.)

TABLE IV-Recorded cases of carcinoma of the oral cavity in highland and coastal provinces of Papua New Guinea between 1965-9 and 1975-9

\begin{tabular}{lrrrrrrrr}
\hline & \multicolumn{4}{c}{$1965-9$} & \multicolumn{3}{c}{$1975-9$} \\
\cline { 2 - 9 } & \multicolumn{2}{c}{ Non } & \multicolumn{1}{c}{ Women } & \multicolumn{3}{c}{ Men } & \multicolumn{2}{c}{ Women } \\
& 108 & 94 & 43 & 93.5 & 208 & 93.3 & 104 & 97.2 \\
& 7 & 6 & 3 & 6.5 & 15 & 6.7 & 3 & 2.8
\end{tabular}

There is evidence that betel nut chewing itself without tobacco additives-as is the custom in Papua-may be oncogenic, ${ }^{17}$ although this view has been challenged. ${ }^{18}$ In many countries where a high incidence of carcinoma of the mouth has been attributed to betel nut chewing it has been observed that tobacco additives are usually present and as a rule the latter have been incriminated as the causative agent. ${ }^{1920}$ In experiments using the hamster buccal pouch one group concluded that tobacco might enhance the carcinogenic effect of betel nut chewing. ${ }^{21}$ Tobacco is not chewed to any extent in Papua New Guinea. Nevertheless, Pindborg et al in a study of buccal mucosa changes in highland and coastal populations noted that coastal people often smoked cigarettes in conjunction with betel nut chewing, ${ }^{16}$ and reported that the prevalence of leucoplakia was significantly higher in coastal populations.

A further factor to consider is alcohol consumption, which in excess is believed to contribute to the oncogenic effect of tobacco in the mouth. ${ }^{23}$ Since the end of prohibition, which was in force for indigenous people until 1963, the consumption of alcohol by both men and women has increased steadily.

The rise in the incidence rate of carcinoma of the oral cavity in women and to a lesser extent in men might therefore be related to increased consumption of tobacco or alcohol, or both, in a population in which habitual betel nut chewing was prevalent. The tumour registry does not record whether patients chewed betel nut, smoked tobacco, or drank alcohol, and accordingly it can not be shown in this study if the rise was related to any of these factors. A case control study to assess the relative risk of varying exposure to these factors would be of value.

At present there is no evidence of a significant increase in the incidence rate of carcinoma of the oesophagus, a neoplasm related to chewing betel nut with tobacco additives ${ }^{24}$ as well as to the consumption of tobacco ${ }^{2}$ and the drinking of alcohol by cigarette smokers."

Interestingly, the reported incidence of lung cancer has not increased. It has long been recognised that carcinoma of the lung occurs in Papua New Guinea, ${ }^{22}{ }^{25}$ although the incidence is low with only 5-10 cases being reported annually. The average annual age standardised incidences were only 1.81 for men and
0.46 for women per 100000 population over the period of study. Surveys in several tropical countries have commented on their apparent low incidence of lung cancer but warned that the change to smoking flue-cured cigarettes, which has been particularly incriminated in the increase in incidence of this neoplasm in developed countries ${ }^{26}$ could lead to a similar increase in those tropical countries. ${ }^{13-15}$

The changing pattern of smoking in Papua has already been documented, ${ }^{10} 2527$ and it has been suggested that the trend to smoking flue-cured cigarettes, which affects both men and women in rural and urban areas, could eventually lead to an increased incidence rate for lung cancer. ${ }^{25}$ Because of the relatively high tobacco consumption per head, Papua New Guinea should provide an excellent model for the study of the incidence rates of neoplasms related to tobacco smoking over the next decade.

\section{References}

${ }^{1}$ Royal College of Physicians of London. Smoking and health now. A new report and summary on smoking and its effects on health. London: Pitman Medical and Scientific Publishing Co, 1971.

2 US Department of Health, Education and Welfare. The health conse- 3 quences of smoking. A report to the Surgeon General. Washington: iN DHEW, 1971, 1972, 1973. (DHEW publications Nos (HSM) 71-7513; o $72-7516$; and 73-8704.)

${ }^{3}$ US Department of Health and Human Services. The health consequences of smoking. The changing cigarette. A report to the Surgeon General. Washington, DC: Public Health Service, 1981.

- Larsen PS, Silvette H. Tobacco. Experimental and clinical studies. Suppl 3. Baltimore: The Williams and Wilkins Co, 1975.

${ }^{5}$ Alexander CS. Cigarettes and heart disease. N Engl f Med 1971;284:1384.

${ }^{6}$ Cragg J. Lung cancer in Jersey; its incidence and associated biochemistry. Br F Clin Pract $1971 ; \mathbf{2 5 : 3 6 0 - 5 .}$

; Thorarinsson H. Carcinoma of the lung in Iceland. A summary and some reflections concerning more recent principles for diagnosis and treatment. Scand f Thorac Cardiovasc Surg 1969;3:31-8.

* Kreyberg L. Comments on the histological typing of lung tumours. Acta Pathol Microbiol Scand (A) $1971 ; 79: 409-56$.

${ }^{9}$ Lowry LD, Marks JE, Powell WJ. 260 laryngeal carcinomas. Staging and end results. Surg Forum $1971 ; 22: 455-6$.

10 Brott K. Tobacco smoking in Papua New Guinea. Papua New Guinea Med f $1981 ; 24: 229-36$

${ }^{11}$ Katz D, Baptista J, Azen SP, Pike MC. Obtaining confidence intervals for the risk ratio in cohort studies. Biometrics 1978;34:469-74.

12 Muller M. Tobacco and the Third World: tomorrow's epidemic. London: $\mathbb{D}$ War on Want Publication, 1978.

13 Woodcock AA. Smoking in Tutong, Brunei: a changing habit. Med $\mathfrak{F}$ Malaysia $1980 ; 34: 205-10$.

14 Pathmanathan I. Smoking habits among medical students in the University of Malaya. Med 7 Malaysia $1975 ; \mathbf{3 0}: 88-92$

${ }^{15}$ Speight ANP. Carcinoma of bronchus in Dar es Salaam. E Afr Med F 1974; $51: 903-8$

16 Pindborg JJ, Barmes D, Roed-Petersen B. Epidemiology and histology of oral leukoplakia and leukoedema among Papuans and New Guineans. Cancer 1968;22:379-84.

17 Schonland $M$, Bradshaw E. Upper alimentary tract cancer in Natal Indians with special reference to the betel chewing habit. $\mathrm{Br} \mathcal{F}$ Cancer 8 $1969 ; 23: 670-82$.

18 Burton-Bradley B. Is betel chewing carcinogenic? Lancet 1979;ii:903.

19 Ramanathan K. Oral carcinoma in the first three decades of life. Med $\mathcal{f}$ 윽 Malaysia $1972 ; 27: 20-6$.

20 Wahi PN, Mital VP, Lahiri B, Luthra UK, Seth RK, Arora GD. Epi- م demiological study of precancerous lesions of the oral cavity: a pre- $\frac{D}{9}$ liminary report. Indian 7 Med Res 1970;58:1361-91.

21 Suri K, Goldman HM, Wells $\mathrm{H}$. Carcinogenic effect of a dimethyl $\mathrm{N}$ sulphoxide extract of betel nut on the mucosa of the hamster buccal o pouch. Nature $1971 ; 230: 383-4$

22 Wigley SC, Randmae G. Lung cancer and the Melanesian. Papua New Guinea Med f $1961 ; 5: 5-10$

${ }^{23}$ Rothman K, Kellar A. The effect of joint exposure to alcohol and tobacco on risk of cancer of the mouth and pharynx. F Chronic Dis 1972;25:711-6. \&

24 Stephen SJ, Uragoda CG. Some observations on oesophageal carcinoma in Ceylon, including its relationship to betel chewing. Br F Cancer 1970;24: $11-5$

25 Wigley SC. Lung cancer and the Melanesian; an impending problem ? Papua New Guinea Med f 1974;17:296-303.

Rokicki W. W sprawie swiazy miedzy technologia wyrobow tytoniowych a zapasalnoscia na raka pluc. Przegl Lek 1971;20:311-3.

27 Anderson HR. Smoking habits and their relationship to chronic lung disease in a tropical environment in Papua New Guinea. Bulletin de Physiopathologie Respiratoire (Nancy) 1974;10:619-33.

(Accepted 3 February 1983)

\section{, , 西

